\title{
Use of dentifrices to prevent erosive tooth wear: harmful or helpful?*
}

\section{Ana Carolina Magalhães(a) Annette Wiegand(b) Marília Afonso Rabelo Buzalaf(a)}

(a) Department of Biological Sciences, Bauru School of Dentistry, Universidade de São Paulo - USP, Bauru, SP, Brazil.

(b) Department of Preventive Dentistry, Periodontology and Cariology, University of Göttingen, Göttingen, Germany.

* Paper presented at the "Equity, Social Inclusion and Oral Health Promotion: Major Challenges" International Symposium, Held at the $18^{\text {th }}$ Congress of the Brazilian Association for Oral Health Promotion (Associação Brasileira de Odontologia de Promoção de Saúde - ABOPREV), April 2013, Bauru, SP, Brazil.

Declaration of Interests: The authors certify that they have no commercial or associative interest that represents a conflict of interest in connection with the manuscript.

Corresponding Author:

Ana Carolina Magalhães

E-mail:acm@usp.br

htrp://dx.doi.org/10.1590/S1806-83242013005000035 Epub Jan 14, 2014

Submitted: Jun 04, 2013

Accepted for publication: Sep 28, 2013

Last revision: Oct 18, 2013
Abstract: Dental erosion is the loss of dental hard tissues caused by nonbacterial acids. Due to acid contact, the tooth surface becomes softened and more prone to abrasion from toothbrushing. Dentifrices containing different active agents may be helpful in allowing rehardening or in increasing surface resistance to further acidic or mechanical impacts. However, dentifrices are applied together with brushing and, depending on how and when toothbrushing is performed, as well as the type of dentifrice and toothbrush used, may increase wear. This review focuses on the potential harmful and helpful effects associated with the use of dentifrices with regard to erosive wear. While active ingredients like fluorides or agents with special anti-erosive properties were shown to offer some degree of protection against erosion and combined erosion/abrasion, the abrasive effects of dentifrices may increase the surface loss of eroded teeth. However, most evidence to date comes from in vitro and in situ studies, so clinical trials are necessary for a better understanding of the complex interaction of active ingredients and abrasives and their effects on erosive tooth wear.

Descriptors: Tooth Erosion; Tooth Abrasion; Dentifrices.

\section{Introduction}

Dental erosion is the loss of dental tissue caused by extrinsic (dietary or environmental) or intrinsic (gastric) acids. This loss occurs in a continuous process and two distinct phases can be distinguished. In the initial phase (erosion), enamel softening occurs without surface loss. Successive erosive attacks lead to surface loss in the advanced phase (erosive tooth wear), and the remaining surface is still softened. ${ }^{1}$

Although the ultimate causal agent for dental erosion are non-bacterial acids, in fact the etiology is multifactorial, involving a complex interaction among behavioral, chemical and biological factors. ${ }^{2}$ Preventive measures for dental erosion are targeted against these causal factors and may include dietary intervention, modification of acidic drinks, behavioral changes and modification of the tooth surface to increase its resistance to acidic attacks. ${ }^{3}$

Among the preventive measures related to behavioral factors, oral hygiene habits are of special interest. Dentifrices containing different active agents may be helpful to allow rehardening and to increase the resistance of the eroded surface to further acids or mechanical impacts. However, dentifrices are applied together with brushing and, depending on how 
and when toothbrushing is performed, as well as the type of dentifrice and toothbrush used, dentifrices may either increase or decrease the degree of wear. The potential harmful and helpful effects of dentifrices containing different active ingredients and abrasivity on erosive tooth wear are discussed in this review.

\section{Review of literature and discussion Dentifrice abrasivity}

Toothbrushing plays an important role in maintaining oral health, and fluoride exposure by dentifrices provides not only protection against caries, but also some protection against dental erosion. On the other hand, abrasive wear of sound and, especially, of eroded dental hard tissues is considered a potential adverse side effect of toothbrushing. ${ }^{4}$ Erosive demineralization of enamel and dentin is accompanied by surface softening, which accounts for the increased susceptibility to abrasion, especially immediately after an erosive challenge..$^{5-7}$ However, at least for eroded dentin, increasing waiting periods prior to brushing probably facilitates rehardening of the surface and, thus, enhancement of abrasion resistance. ${ }^{6}$ Alternatively, patients suffering from severe erosion may benefit by brushing their teeth immediately before rather than after an erosive attack to avoid abrasion of softened tissue. ${ }^{8}$

As shown for sound dental hard tissues, ${ }^{9-11}$ toothbrushing abrasion of eroded enamel and dentin is mainly influenced by the abrasivity of the dentifrice and, to a lesser extent, by the toothbrush itself. ${ }^{12,13}$ Depending on the characteristics of the toothbrush, such as type, filament stiffness, and filament endrounding, the toothbrush as a delivery vehicle only modulates the abrasivity of the dentifrice. ${ }^{11-13}$

In vitro studies clearly demonstrated that abrasion of eroded enamel and dentin increased with increasing REA (relative enamel abrasion) or RDA (relative dentin abrasion) values, respectively, of the dentifrice. ${ }^{12-16}$ However, in the case of enamel, this effect was less pronounced when the abrasion of dentifrices with different abrasivity on eroded specimens was investigated in situ..$^{17,18}$ A possible explanation could be that over a short (clinically relevant) period of time, a softened layer of less than $0.5 \mu \mathrm{m}$ thickness of eroded enamel is easily removed, independently of the abrasivity of the dentifrice. ${ }^{19}$ In this context, it is worth mentioning that toothbrushing abrasion of eroded dental hard tissues is also related to brushing force, but these aspects are discussed in detail elsewhere. ${ }^{20,21}$

However, interpretation of dentifrice abrasivity studies is challenging, particularly because the REA or RDA values obtained from different sources may vary distinctly. ${ }^{22}$ Moreover, the relationship between enamel abrasion (REA) and dentin abrasion (RDA) is not necessarily direct, e.g., a dentifrice with a high RDA value may have a relatively low REA value and vice versa. ${ }^{11,18}$ On this basis, interpretation of a recent study analyzing the abrasive potential of new anti-erosion dentifrices on eroded enamel is difficult, since only RDA and not REA values were given. ${ }^{22}$ However, RDA values of the special-formulation dentifrices were in the range of conventional dentifrices, which may account for the fact that the special formulations were not superior, and may even be less effective in preventing enamel erosion-abrasion.

The abrasion of eroded enamel and dentin increases with increasing abrasivity of the dentifrice, ${ }^{13,23}$ thus dentifrices with high abrasivity, such as whitening dentifrices, should not be used on a frequent basis. ${ }^{17}$

\section{Active ingredients in dentifrices}

Since dentifrices are widely used for oral hygiene and prevention of dental caries, ${ }^{24}$ it is evident that they should also be used as a vehicle for protective ingredients against dental erosion..$^{25}$

One of the most common active ingredients found in dentifrices is fluoride. Different fluoride compounds have been used, such as $\mathrm{NaF}$ (sodium fluoride), MFP (sodium monofluoride phosphate), $\mathrm{SnF}_{2}$ (stannous fluoride) and $\mathrm{AmF}$ (amine fluoride). Fluoride concentrations in dentifrices typically vary between 550 and $1450 \mathrm{ppm}$ F. However, recent studies have shown a limited beneficial effect of conventional 1100 ppm F dentifrices $(\mathrm{NaF})$ compared with non-fluoridated dentifrices with regard to abrasion of eroded dentin and enamel (an approximate 
$30 \%$ reduction in wear when compared with a placebo). ${ }^{26,27}$

Based on these findings, highly concentrated fluoride dentifrices (5000 ppm F, NaF) have been tested, but the results obtained so far are inconclusive. In an in situ study, a commercial dentifrice with $5000 \mathrm{ppm} F$ had the same positive effect as another commercial 1100 ppm F dentifrice $(\mathrm{NaF})$ on eroded and eroded-abraded dentin. ${ }^{28}$ With respect to enamel, no significant differences were found among 0 , 1100 and 5000 ppm $\mathrm{F}$ dentifrices on erosion and erosion-abrasion in situ. ${ }^{29}$ In contrast, an experimental 5000 ppm F dentifrice was able to significantly reduce enamel erosion and erosion-abrasion compared to a conventional $1100 \mathrm{ppm} \mathrm{F}$ dentifrice in vitro. ${ }^{30}$ It has been discussed that the amount of fluoride available in the dentifrice slurry is not directly related to the possible protective effect of dentifrices against enamel erosion. ${ }^{22}$ Therefore, the effect of highly concentrated fluoride dentifrices on dental erosion and abrasion is still under debate.

Regarding the type of fluoride compound, most of the studies were conducted using $\mathrm{NaF}$ dentifrices. It is believed that the mechanism of action of fluoride against erosion occurs by inducing the formation of a layer on the eroded surface, which is composed of $\mathrm{CaF}_{2}$ (in the case of conventional compounds, such as $\mathrm{AmF}$ or $\mathrm{NaF}$ ) or of metal-rich surface precipitates (in the case of $\mathrm{SnF}_{2}$ ). These layers should behave as a physical barrier, hampering the contact of acid with the underlying enamel, or as a mineral reservoir that is attacked by the erosive challenge, thus buffering the acids or promoting mineral precipitation. ${ }^{31}$ However, fluoridation by dentifrices is less effective in preventing enamel and dentin erosion than intensive fluoridation with the additional use of fluoridated gels and rinses. ${ }^{32}$

The use of tin-containing fluoride products seems to provide the best approach for effective prevention of dental erosion compared with conventional fluorides, such as $\mathrm{NaF}^{31,33,34} \mathrm{SnF}_{2}$ dentifrices markedly reduced the dissolution of teeth in vivo, whereas $\mathrm{NaF}$ dentifrices provided no protection. ${ }^{35}$ More recently, $\mathrm{SnF}_{2}$ dentifrices were shown to be superior in reducing dental erosion when compared with $\mathrm{NaF}$ dentifrices, but not combined erosion and abrasion, ${ }^{22}$ although another study showed that $\mathrm{SnF}_{2}$-containing dentifrices significantly reduced erosive and abrasive wear compared to $\mathrm{NaF}$ dentifrices. ${ }^{36}$ Thus, evidence available so far suggests that $\mathrm{SnF}_{2}$ seems to be the best fluoride salt that should be incorporated into dentifrices for preventing erosion and abrasion, at least for enamel. Moreover, when new formulations aimed at preventing erosion are developed, the possible interaction among the different components should be considered. It was reported that the combination of $\mathrm{NaF}$ with the desensitizing agent $\mathrm{KNO}_{3}$ impairs the effect of fluoride on the reduction of wear. ${ }^{37}$

It is important to bear in mind that other factors such as $\mathrm{pH}$, consistency and abrasivity may modulate the effect of fluoride dentifrices on dental erosion and abrasion. In a recent study it was shown that fluoride concentration and consistency influenced enamel and dentin wear, while the $\mathrm{pH}$ seemed to have no effect, ${ }^{38}$ as had been previously shown for commercial dentifrices with $\mathrm{pH}$ ranging between 4 and $7 .{ }^{39}$ In addition, the effects of fluoride may be partly masked by the abrasivity of the dentifrice. ${ }^{14,38}$ Some reduction of available ions (tin) may occur in dentifrices due to their adsorption to the negatively charged silica.

Recently, new dentifrices claiming anti-erosive properties have been marketed, but few studies have evaluated their effectiveness so far. These new dentifrices usually contain $\mathrm{KNO}_{3}$ (anti-hypersensitivity agent), hydroxyapatite (HAP) with or without fluoride, $\mathrm{Zn}$-carbonate hydroxyapatite, calcium sodium phosphosilicate (remineralizing agents) and chitosan.

Dentifrices containing $\mathrm{NaF}$ and $5 \% \mathrm{KNO}_{3}$ have shown potential to reharden eroded enamel surfaces; ${ }^{40-42}$ however, for the prevention of enamel erosive wear, they have almost no effect compared to placebo. ${ }^{2,37,43}$ This may be due to the interaction between $\mathrm{NaF}$ and $\mathrm{KNO}_{3}$, which reduces the bioavailability of fluoride. ${ }^{37}$

Remineralizing agents, such as hydroxyapatite (with or without F) and Zn-carbonate hydroxyapatite, are expected to induce some mineral precipitation on enamel. ${ }^{44}$ However, the incorporation of new hydroxyapatite into demineralized enamel is 
not able to increase the resistance to erosive dissolution. ${ }^{22}$ The same was shown for calcium sodium phosphosilicate. Although it was deposited on enamel and on dentin surfaces as well, ${ }^{45}$ this either had no preventive or repairing effect on erosion ${ }^{46}$ or the effect against erosion was similar to that of conventional fluoride dentifrices. ${ }^{47}$ Therefore, so far there is no evidence that the incorporation of salts that could be converted into hydroxyapatite or that the direct incorporation of hydroxyapatite or nano-hydroxyapatite into dentifrices significantly contributes to reduce enamel solubility under erosive challenges. ${ }^{22}$

Chitosan is a natural polysaccharide produced by deacetylation of chitin. It presents a positive charge at a low $\mathrm{pH}$, readily adsorbing to enamel. ${ }^{48} \mathrm{It}$ is speculated that chitosan can build up a protective organic layer through interaction with enamel and proteins from the acquired pellicle. ${ }^{49,50}$ Moreover, due to its lubricating effects, it may reduce the abrasivity of dentifrices by binding to the silica particles or the tooth surface. ${ }^{51}$ Therefore, chitosan may also enhance the effect of stannous fluoride-containing dentifrices, which were shown to have a distinct anti-erosive effect on enamel and dentin. ${ }^{51}$ However, the inclusion of chitosan in non-fluoridated dentifrices did not show further protective effects against enamel erosive wear compared to conventional fluoride dentifrices. ${ }^{22}$

Other dentifrices, containing arginine and strontium, have been recently marketed as anti-hypersensitivity products, but nearly no study has so far been conducted to evaluate their potential against dental erosion. Strontium acetate and arginine-based dentifrices resulted in significant dentin tubular occlusion, but the arginine-based dentifrice was more

\section{References}

1. Lussi A, Schlueter N, Rakhmatullina E, Ganss C. Dental erosion-an overview with emphasis on chemical and histopathological aspects. Caries Res. 2011;45 Spec Iss 1:2-12.

2. Lussi A. Erosive tooth wear - a multifactorial condition of growing concern and increasing knowledge. Monogr Oral Sci. 2006;20:1-8.

3. Magalhães AC, Wiegand A, Rios D, Honório HM, Buzalaf MA. Insights into preventive measures for dental erosion. J Appl Oral Sci. 2009 Mar-Apr;17(2):75-86. susceptible to acid challenge compared to strontium. Both dentifrices presented behavior similar to that of a placebo with respect to acid resistance. ${ }^{52}$ On the other hand, strontium-containing dentifrices were shown to have better efficacy in occluding dentinal tubules compared to arginine-based dentifrices, which may be an indication of better effectiveness against erosion. ${ }^{53}$

\section{Conclusion}

To date, most of the information regarding the use of dentifrices to prevent erosive tooth wear comes from in vitro and in situ studies, so the available evidence has to be confirmed by further clinical studies.

From the available literature, it can be concluded that the possible benefits of dentifrices exceed adverse side effects by far, not only because active ingredients for the prevention of erosion and-more importantly-caries can be included, but also because their abrasives ensure biofilm removal and tooth cleaning.

In the case of dental erosion, various active ingredients have been tested so far, which ideally act by forming acid-resistant surface precipitates. While studies proved that fluoridated dentifrices offer some degree of protection, most of the other potential active ingredients have hardly been investigated so far, so no final conclusions can be drawn. Abrasion effects are considered a potential side effect of dentifrices, but clinical studies did not prove the significance of toothbrushing abrasion on overall tooth wear. However, in situ studies indicate that the use of high abrasive dentifrices should be avoided to prevent further wear of eroded enamel and dentin.

4. Addy M, Hunter ML. Can tooth brushing damage your health? Effects on oral and dental tissues. Int Dent J. 2003;53 Spec Iss 3:177-86.

5. Attin T, Knofel S, Buchalla W, Tutuncu R. In situ evaluation of different remineralization periods to decrease brushing abrasion of demineralized enamel. Caries Res. 2001 MayJun;35(3):216-22. 
6. Attin T, Siegel S, Buchalla W, Lennon AM, Hannig C, Becker $\mathrm{K}$. Brushing abrasion of softened and remineralised dentin: an in situ study. Caries Res. 2004 Jan-Feb;38(1):62-6.

7. Rios D, Honório HM, Magalhães AC, Delbem AC, Machado MA, Silva SM, et al. Effect of salivary stimulation on erosion of human and bovine enamel subjected or not to subsequent abrasion: an in situ/ex vivo study. Caries Res. 2006 MayJun;40(3):218-23.

8. Wiegand A, Egert S, Attin T. Toothbrushing before or after an acidic challenge to minimize tooth wear? An in situ/ex vivo study. Am J Dent. 2008 Feb;21(1):13-6.

9. Addy M, Hughes J, Pickles MJ, Joiner A, Huntington E. Development of a method in situ to study toothpaste abrasion of dentine. Comparison of 2 products. J Clin Periodontol. 2002 Oct;29(10):896-900.

10. Joiner A, Pickles MJ, Lynch S, Cox TF. The measurement of enamel wear by four toothpastes. Int Dent J. 2008 Feb;58(1):23-8.

11. Philpotts CJ, Weader E, Joiner A. The measurement in vitro of enamel and dentine wear by toothpastes of different abrasivity. Int Dent J. 2005;55(3 Suppl 1):183-7.

12. Wiegand A, Schwerzmann M, Sener B, Magalhães AC, Roos $\mathrm{M}$, Ziebolz D, et al. Impact of toothpaste slurry abrasivity and toothbrush filament stiffness on abrasion of eroded enamel an in vitro study. Acta Odontol Scand. 2008 Aug;66(4):231-5.

13. Wiegand A, Kuhn M, Sener B, Roos M, Attin T. Abrasion of eroded dentin caused by toothpaste slurries of different abrasivity and toothbrushes of different filament diameter. $\mathrm{J}$ Dent. 2009 Jun;37(6):480-4.

14. Hara AT, Gonzalez-Cabezas C, Creeth J, Parmar M, Eckert GJ, Zero DT. Interplay between fluoride and abrasivity of dentifrices on dental erosion-abrasion. J Dent. 2009 Oct;37(10):781-5.

15. Hughes N, Mason S, Creeth J, Hara AT, Parmar M, Gonzalez-Cabezas C. The effect of anti-sensitivity dentifrices on brushing abrasion of eroded dentin in vitro. J Clin Dent. 2008;19(4):143-6.

16. Menezes M, Turssi CP, Hara AT, Messias DC, Serra MC. Abrasion of eroded root dentine brushed with different toothpastes. Clin Oral Investig. 2004 Sep;8(3):151-5.

17. Turssi CP, Faraoni JJ, Rodrigues Jr AL, Serra MC. An in situ investigation into the abrasion of eroded dental hard tissues by a whitening dentifrice. Caries Res. 2004 Sep-Oct;38(5):473-7.

18. Hooper S, West NX, Pickles MJ, Joiner A, Newcombe RG, Addy M. Investigation of erosion and abrasion on enamel and dentine: a model in situ using toothpastes of different abrasivity. J Clin Periodontol. 2003 Sep;30(9):802-8.

19. Wiegand A, Wegehaupt F, Werner C, Attin T. Susceptibility of acid-softened enamel to mechanical wear--ultrasonication versus toothbrushing abrasion. Caries Res. 2007;41(1):56-60.

20. Ganss C, Hardt M, Blazek D, Klimek J, Schlueter N. Effects of toothbrushing force on the mineral content and demin- eralized organic matrix of eroded dentine. Eur J Oral Sci. 2009 Jun;117(3):255-60.

21. Wiegand A, Köwing L, Attin T. Impact of brushing force on abrasion of acid-softened and sound enamel. Arch Oral Biol. 2007 Nov;52(11):1043-7.

22. Ganss C, Lussi A, Grunau O, Klimek J, Schlueter N. Conventional and anti-erosion fluoride toothpastes: effect on enamel erosion and erosion-abrasion. Caries Res. 2011;45(6):581-9.

23. Wiegand A, Lemmrich F, Attin T. Influence of rotating-oscillating, sonic and ultrasonic action of power toothbrushes on abrasion of sound and eroded dentine. J Periodontal Res. 2006 Jun;41(3):221-7.

24. Walsh T, Worthington HV, Glenny AM, Appelbe P, Marinho VC, Shi X. Fluoride toothpastes of different concentrations for preventing dental caries in children and adolescents. Cochrane Database Syst Rev. 2010 Jan 20;(1):CD007868.

25. Bartlett DW, Smith BG, Wilson RF. Comparison of the effect of fluoride and non-fluoride toothpaste on tooth wear in vitro and the influence of enamel fluoride concentration and hardness of enamel. Br Dent J. 1994 May 7;176(9):346-8.

26. Ponduri S, Macdonald E, Addy M. A study in vitro of the combined effects of soft drinks and tooth brushing with fluoride toothpaste on the wear of dentine. Int J Dent Hyg. 2005 Feb;3(1):7-12.

27. Magalhães AC, Rios D, Delbem ACB, Buzalaf MAR, Machado MAAM. Influence of fluoride dentifrice on brushing abrasion of eroded human enamel: an in situ/ex vivo study. Caries Res. 2007;41(1):77-9.

28. Magalhães AC, Rios D, Moino AL, Wiegand A, Attin T, Buzalaf MAR. Effect of different concentrations of fluoride in dentifrices on dentin erosion subjected or not to abrasion in situ/ex vivo. Caries Res. 2008;42(2):112-6.

29. Rios D, Magalhães AC, Polo RO, Wiegand A, Attin T, Buzalaf MAR. The efficacy of a highly concentrated fluoride dentifrice on bovine enamel subjected to erosion and abrasion. J Am Dent Assoc. 2008 Dec;139(12):1652-6.

30. Moretto MJ, Magalhães AC, Sassaki KT, Delbem ACB, Martinhon CCR. Effect of different fluoride concentrations of experimental dentifrices on enamel erosion and abrasion. Caries Res. 2010;44(2):135-40.

31. Magalhães AC, Wiegand A, Rios D, Buzalaf MA, Lussi A. Fluoride in dental erosion. Monogr Oral Sci. 2011;22:158-70.

32. Ganss C, Klimek J, Brune V, Schürmann A. Effects of two fluoridation measures on erosion progression in human enamel and dentine in situ. Caries Res. 2004 Nov-Dec;38(6):561-6.

33. Schlueter N, Hardt M, Lussi A, Engelmann F, Klimek J, Ganss C. Tin-containing fluoride solutions as anti-erosive agents in enamel: an in vitro tin-uptake, tissue-loss, and scanning electron micrograph study. Eur J Oral Sci. 2009 Aug;117(4):427-34.

34. Ganss C, Neutard L, von Hinckeldey J, Klimek J, Schlueter N. Efficacy of a tin/fluoride rinse: a randomized in situ trial on erosion. J Dent Res. 2010 Nov;89(11):1214-8. 
35. Young A, Thrane PS, Saxegaard E, Jonski G, Rölla G. Effect of stannous fluoride toothpaste on erosion-like lesions: an in vivo study. Eur J Oral Sci. 2006 Jun;114(3):180-3.

36. Huysmans MC, Jager DH, Ruben JL, Unk DE, Klijn CP, Vieira AM. Reduction of erosive wear in situ by stannous fluoridecontaining toothpaste. Caries Res. 2011;45(6):518-23.

37. Kato MT, Lancia M, Sales-Peres SH, Buzalaf MA. Preventive effect of commercial desensitizing toothpastes on bovine enamel erosion in vitro. Caries Res. 2010;44(2):85-9.

38. Moron BM, Miyazaki SSH, Ito N, Wiegand A, Vilhena F, Buzalaf MAR, et al. Impact of different fluoride concentrations and $\mathrm{pH}$ of dentifrices on tooth erosion/abrasion in vitro. Aust Dent J. 2013 Mar;58(1):106-11.

39. Lussi A, Megert B, Eggenberger D, Jaeggi T. Impact of different toothpastes on the prevention of dental erosion. Caries Res. 2008;42(1):62-7.

40. Zero DT, Hara AT, Kelly SA, González-Cabezas C, Eckert GJ, Barlow AP, et al. Evaluation of a desensitizing test dentifrice using an in situ erosion remineralization model. J Clin Dent. 2006;17(4):112-6.

41. Hara AT, Kelly SA, González-Cabezas C, Eckert GJ, Barlow AP, Mason SC, et al. Influence of fluoride availability of dentifrices on eroded enamel remineralization in situ. Caries Res. 2009;43(1):57-63.

42. Maggio B, Guibert RG, Mason SC, Karwal R, Rees GD, Kelly $S$, et al. Evaluation of mouthrinse and dentifrice regimens in an in situ erosion remineralisation model. J Dent. 2010 Nov;38 Spec Iss 3:S37-44.

43. Rees J, Loyn T, Chadwick B. Pronamel and tooth mousse: an initial assessment of erosion prevention in vitro. J Dent. 2007 Apr;35(4):355-7.

44. Poggio C, Lombardini M, Colombo M, Bianchi S. Impact of two toothpastes on repairing enamel erosion pro- duced by a soft drink: an AFM in vitro study. J Dent. 2010 Nov;38(11):868-74.

45. Sedel L, Rey C, editors. Bioceramics. Vol. 10, Proceedings of the 10th International Symposium on ceramics in medicine. New York: Elsevier; 1997. Litkowski LJ, Hack GD, Sheaffer $\mathrm{HB}$, Greenspan DC. Occlusion of dentin tubules by $45 \mathrm{~S} 5$ Bioglass; p. 411-4.

46. Wang X, Megert B, Hellwig E, Neuhaus KW, Lussi A. Preventing erosion with novel agents. J Dent. 2011 Feb;39(2):163-70.

47. Turssi CP, Maeda FA, Messias DC, Neto FC, Serra MC, Galafassi D. Effect of potential remineralizing agents on acid softened enamel. Am J Dent. 2011 Jun;24(3):165-8.

48. Young A, Smistad G, Karlsen J, Rölla G, Rykke M. Zeta potentials of human enamel and hydroxyapatite as measured by the Coulter DELSA 440. Adv Dent Res. 1997 Nov;11(4):560-5.

49. van der Mei HC, Engels E, de Vries J, Dijkstra RJ, Busscher HJ. Chitosan adsorption to salivary pellicles. Eur J Oral Sci. 2007 Aug;115(4):303-7.

50. Svensson O, Lindh L, Cárdenas M, Arnebrant T. Layer-bylayer assembly of mucin and chitosan--Influence of surface properties, concentration and type of mucin. J Colloid Interface Sci. 2006 Jul 15;299(2):608-16.

51. Schlueter N, Klimek J, Ganss C. Effect of a chitosan additive to a $\mathrm{Sn}(2+)$-containing toothpaste on its anti-erosive/antiabrasive efficacy-a controlled randomised in situ trial. Clin Oral Investig. 2013 Feb 17.

52. Olley RC, Pilecki P, Hughes N, Jeffery P, Austin RS, Moazzez R, et al. An in situ study investigating dentine tubule occlusion of dentifrices following acid challenge. J Dent. 2012 Jul;40(7):585-93.

53. Davies M, Paice EM, Jones SB, Leary S, Curtis AR, West NX. Efficacy of desensitizing dentifrices to occlude dentinal tubules. Eur J Oral Sci. 2011 Dec;119(6):497-503. 